AC 2010-1457: ASSESSMENT-DRIVEN EVOLUTION OF A FIRST-YEAR PROGRAM

Rick Williams, East Carolina University

William Howard, East Carolina University 


\title{
Assessment Driven Evolution of a First year Program
}

\begin{abstract}
The general engineering program at East Carolina University (ECU) was established in 2004. In the fall of 2007, a major curriculum change was initiated that introduced three new courses into the first year. These courses are Engineering Graphics, Introduction to Engineering, and Computer Applications in Engineering. Each of these courses contains projects or assignments that directly assess the achievement of ABET outcomes. In addition, student surveys provide indirect assessment of student achievement of ABET outcomes as well as course level objectives. Engineering Graphics provides direct assessment of outcome k (modern engineering tools), Introduction to Engineering provides direct assessment of outcomes $\mathrm{f}$ (professional ethics), $g$ (effective communications), and $\mathrm{h}$ (impact of engineering solutions), and Computer Applications in Engineering provides direct assessment of outcomes g (effective communications) and $\mathrm{k}$ (modern engineering tools). This paper presents the details of the assessment assignments in each course, the results of both direct and indirect assessment, the changes made to affect continuous improvement, and the results, both good and bad, of the changes on subsequent assessment. Taken as a whole, this work demonstrates how making assessment-driven changes to first-year courses can markedly improve the program. The results of all of the assessment tools and improvements are discussed in detail within the paper.
\end{abstract}

\section{Introduction}

The B.S. is engineering program at ECU was initiated in Fall 2004. A general, rather than a discipline-specific, program was selected in order to match the demands for flexible problem solvers of the primarily small and medium-sized companies of the geographic area. The curriculum adopted included a common engineering core, with four concentration areas for a limited degree of specialization in the junior and senior years. The curriculum was also designed to incorporate best practices from the National Science Foundation's Engineering Education Coalitions. ${ }^{1}$ Among these best practices was the "Implementation of 'engineering up front': the exposure of freshmen to hands-on, real world engineering practice early in their undergraduate education, ranging from 'professional level' laboratory facilities to realistic design projects." Two freshman courses designed to provide students early exposure to engineering concepts were created. Both were six-credit courses. The first, ICEE 1010 (ICEE stands for Integrated Collaborative Engineering Environment), was taught in three one-hour lectures and three twohour lab sessions per week. Topics included graphics, introductions to mechanical and electrical engineering concepts, professional practice topics (such as teamwork, ethics, and project management), and a robot project. The second course, ICEE 1020, was taught in five one-hour lectures and one two-hour lab session per week and included statics, mechanics of materials, materials science, and engineering economics.

In an "ideal" environment (all students beginning in fall semester at the same math level, all students highly motivated to learn engineering, and no transfer students), these freshman courses 
could probably be taught successfully. In practice, the six-credit freshman courses presented several problems:

- Because there were no admission requirements to the engineering program beyond those of the university, many students chose engineering as a major during summer registration. These students tended to have very little commitment to engineering, and many dropped the class or quit coming to class regularly. This high attrition was disruptive to the fostering of teamwork in the first semester course.

- Students who did drop the course would usually go below the 12-hour threshold for fulltime status.

- Transfer students did not typically bring in all elements of either six-credit course, and so were often required to repeat topics for which they had previously received credit.

The logistical problems described above could have possibly been solved through higher admission standards and the creation of special course for transfer students. The major motivation for a re-design of the freshman year was concern over the topics covered in the classes. The inclusion of so many topics in the freshman year certainly was surprising to any faculty member accustomed to a more traditional engineering program; however, a case could be made that because all of the topics could be taught at a pre-calculus level, early exposure to these topics could help to motivate students. Following the 2005-2006 academic year, the authors conducted an evaluation of the course objectives of the engineering core classes relative to the coverage of topics on the Fundamentals of Engineering (FE) examination. This examination exposed several shortcomings in the topics covered in the curriculum, and also revealed that approximately $45 \%$ of the coverage of FE topics took place during the freshman year. This result was of concern since passing the FE exam had been deemed as an important goal for graduates of the program.

During the 2006-2007 year, curriculum revisions were planned. New courses in material and processes, statics, mechanics of materials, and engineering economics were placed in the sophomore and junior years. For the freshman year, a re-evaluation of the goals for freshmanlevel courses was necessary, and included a review of the freshman programs at other institutions. The goals that were agreed to among program faculty included:

- retaining an early exposure to engineering topics in order to sustain interest in engineering and provide a context for the required math, science and general education courses that make up the bulk of first-year courses,

- developing some specific software skills that will be built upon in subsequent courses,

- allowing students to feel connected to the program through team activities and interaction with faculty in small classes, and

- supporting achievement of applicable program outcomes.

Brannan and $\mathrm{Wankat}^{3}$ reported the results of two extensive surveys of first-year programs, and found that about two-thirds of engineering programs have an Introduction to Engineering course. Computer tools or programming classes were found in $61 \%$ of programs, but design and graphics were found in less than half of the programs surveyed: 
Despite the large number of papers on first-year engineering design, less than half (40.8\%) of the schools have some type of first-year engineering design. Computer drawing/graphics is also required by less than half (46.9\%) of the programs.

The inclusion of design activities in the freshman year was given careful evaluation. Activities in which design is approached as a trial-and-error exercise and omit analysis and evaluation can trivialize the design process. On the other hand, as described by Crockett et al. ${ }^{4}$ design projects can help students begin to see problem-solving from an inter-disciplinary approach:

A universal characteristic of engineering application is that tools and phenomena are used long before they are completely understood. (Thermodynamics owes more to the steam engine than the steam engine owes to thermodynamics!) One insidious result of delaying design exposure is that students mimic their instructors and carry forward a serious intellectual flaw. They begin to classify and compartmentalize knowledge, and neither integrate information nor make connections between disciplines. This is particularly critical in the freshman year, where students are exposed to mathematics, chemistry, physics and computer science - taught in isolation. These subjects should under gird their design skills and form connective threads in the tapestry of their professional awareness. Instead, they build silos in their consciousness, become unwilling to approach comprehensive problems and are incapable of holistic solutions.

Despite the shortcomings of the six-credit course structure, the robot design project was deemed successful and worth retaining in the new curriculum. However, the project was moved from the first to the second semester. This change resulted from the observation that often the robot teams were dominated by a student or two with good manual skills, while other students seemed to be intimidated by their lack of these skills. Since new engineering students often do not have a clear idea of what an engineer does, there is a danger that they will perceive their lack of manual skills as a barrier that cannot be overcome. Besterfield-Sacre et al. ${ }^{5}$ found that students who left engineering programs in good academic standing had lower confidence in their "engineering abilities" than students who remained in engineering. Dee and Livesay ${ }^{6}$ surveyed students who left engineering and asked them to select the type of courses they would most like to take.

Courses with hands-on experiments and laboratories were the least favored by these students. Certainly hands-on activities are important, but delaying them for a semester may help some atrisk students develop a degree of confidence and familiarity with their fellow students that will help them to overcome their intimidation. Another reason for delaying the projects for a semester is the high attrition of students in the first semester, which causes disruption in student teams, as noted above.

Engineering graphics can also present challenges for some students, especially female students, who have been shown to lag their male counterparts in spatial (3D visualization) ability, as reported by Peters et al. ${ }^{7}$ and others. A significant conclusion from the Peters et al. study was that this difference in spatial ability, as measured by a mental rotation test, did not result in performance differences in math, science, or design courses. As with manual ability, the lack of spatial ability is not a major obstacle to an engineering education, unless the student believes that it is an essential "engineering skill" that he/she lacks in comparison to classmates. Sorby and Baartsman $^{8}$ report success in designing a graphics course to emphasize the development of 
visualization skills. In our decision to continue to teach engineering graphics in the freshman year, we attempted to include exercises specifically designed to improve visualization skills.

The use of computer tools and programming were topics that were largely absent in the six-credit freshman courses of the original curriculum. Some instruction in Excel was included in the first course, but programming (with MATLAB) was not taught until the sophomore year. While a numerical methods course later in the curriculum could include more mathematically rigorous applications, basic computing skills can be applied immediately in the freshman year, and can supplement the math courses that the students taking concurrently. Also, the inclusion of programming allows for a more sophisticated robot project.

The sequence of freshman engineering courses chosen for the revised curriculum was:

- Fall Semester: ICEE 1012 Engineering Graphics (2 credits)

- $\quad$ Spring Semester: ICEE 1014 Introduction to Engineering (3 credits) and ICEE 2050 Computer Applications in Engineering

These courses are described in detail later.

A critical element of the curriculum redesign was the assessment of program outcomes within courses. The program's assessment plan detailed several methods of assessment conducted at the course level:

- Samples of student work, evaluated relative to a specific program outcome by the instructor,

- Targeted exam questions (multiple-choice, FE-style) in courses with topics covered by the FE exam, and

- Student surveys measuring the self-reported achievement of course objectives.

Results from these assessment activities are evaluated by the course coordinator and reported in an end-of-semester report. This report is presented by the course coordinator to all program faculty members at a meeting at the end of every semester. Also, program outcome assessment data is collected and evaluated by an outcome coordinator, and presented to all faculty members at an annual assessment workshop. ${ }^{9}$ At these meetings, the faculty determines whether each outcome is being adequately and efficiently assessed. Often, these meetings lead to adjustments in the assessment plan.

The creation of new courses and the writing of course level objectives to achieve specific ABET outcomes can be a challenging task, especially for first year program courses where there is no universal agreement of the content and topics. Felder and Brent ${ }^{10}$ describe the effort required to create a course to achieve specified outcomes in three domains as:

planning (identifying course content and defining measurable learning objectives for it); instruction (selecting and implementing the methods that will be used to deliver the specified content and facilitate student achievement of the objectives); and assessment and evaluation (selecting and implementing the methods that will be used to determine whether and how well the objectives have been achieved and interpreting the results).

In addition, Felder and Brent make the following points regarding the use of assessment in the continuous improvement loop: 
The three domains are not purely sequential — the information collected in each of them feeds back to each of the others in a cycle that leads to continuous improvement. If the assessment reveals that an objective has not been satisfactorily achieved, the nature of the failure may suggest reframing the objective or modifying the instruction used to address it. Similarly, as the quality of the instructional program improves, new objectives may be formulated to encompass higher levels of achievement and the course instruction and assessment modified accordingly.

In the following sections, each of the three first year courses are described in further detail focusing on the course level objectives, outcomes, and assessment tools utilized to evaluate the achievement of the objectives and outcomes. The results of the assessments are analyzed and discussed, and where the results indicate that an objective has not been satisfactorily achieved, the corrective actions in the form of new instruction techniques, the modification of the objectives, or the changing of the assessment tools are presented.

\section{Course Assessment and Modifications}

\section{Engineering Graphics}

The first engineering course in ECU's program is Engineering Graphics. This course teaches both hand sketching covering topics such as projection theory, multiview drawings, section and auxiliary views, isometric views, and dimensioning and tolerancing as well as solid modeling. The course is taught in a one-hour lecture, two-hour lab format with the lecture primarily covering the hand-sketching topics and the lab primarily covering the solid modeling topics. The intent of this course is not to produce draftsmen, but to produce a student who can interpret multiview drawings and has a strong base in solid modeling techniques such that the solid modeling tool can be utilized in more advanced courses such as dynamics, mechanics of materials, and senior design. This additional exposure further develops the students' proficiency at utilizing solid modeling as a tool for solving advanced engineering problems. The Engineering Graphics course supports ABET outcomes g (communications) and k (modern engineering tools). Both outcomes are indirectly assessed via student surveys and outcome $\mathrm{k}$ is directly assessed via a portfolio.

The graphics portfolio has been utilized as an assessment tool in both graphics courses in the old and new curricula. The portfolio is submitted as a hard copy and includes an appropriate screen capture of the solid modeling exercise and a short written description of the exercise. The students are required to include all of their solid modeling work (both in-lab exercises and homework) in the portfolio. Figure 1 shows an example of what is expected in the portfolio for a typical solid modeling exercise. 


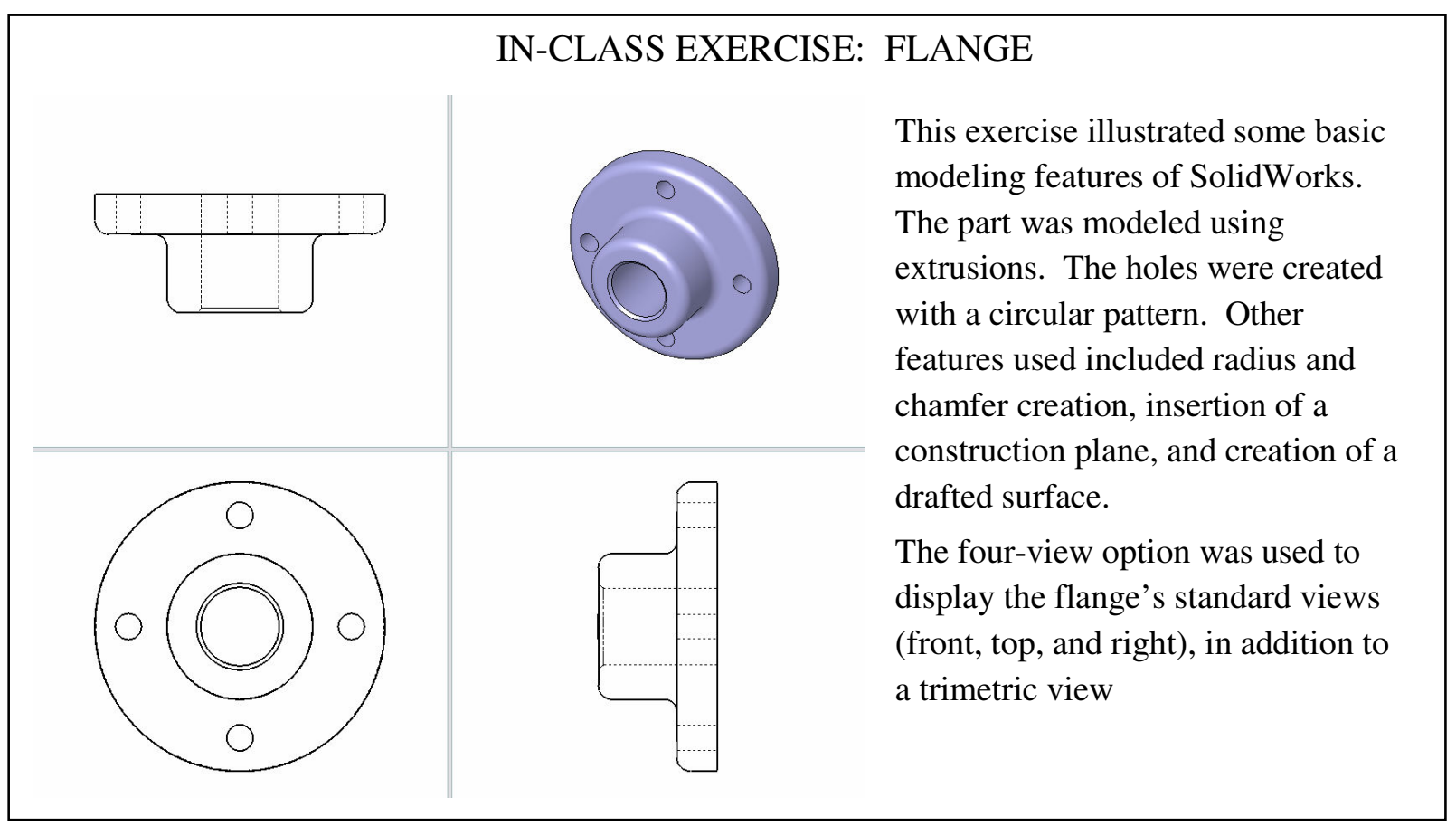

Figure 1: Example page from the Solid Modeling Portfolio showing the screen capture and written description of the exercise.

The portfolios are assessed on a 1 to 4 scale using the rubric shown in Table 1 . The portfolios rated a 3 or 4 are considered acceptable from an assessment standpoint and the assessment results are reported as a percentage of acceptable portfolios. Table 2 shows the percentage of acceptable portfolios dating back across both the old and new curricula.

Table 1: Portfolio Assessment Rubric for Outcome k

\begin{tabular}{|c|l|}
\hline Rating & Portfolio Description \\
\hline 4 & $\begin{array}{l}\text { Portfolio is complete, descriptions are well-written and informative. Project and/or } \\
\text { other independent work demonstrate creative ability and CAD skills at a level } \\
\text { expected for an entry-level engineer. }\end{array}$ \\
\hline 3 & $\begin{array}{l}\text { Portfolio is complete, but a few entries may have errors. Descriptions are well- } \\
\text { written. Project and/or other independent work demonstrate CAD skills expected for } \\
\text { most students after one semester of instruction. }\end{array}$ \\
\hline 2 & $\begin{array}{l}\text { Several items are missing from portfolio. Descriptions are superficial and do not } \\
\text { demonstrate knowledge of the operations used. Project and/or other independent } \\
\text { work demonstrate CAD skills below those expected for most students after one } \\
\text { semester of instruction. }\end{array}$ \\
\hline 1 & $\begin{array}{l}\text { Many items are missing. Descriptions are missing and/or poorly written, and do not } \\
\text { demonstrate knowledge of the operations used. Project and/or other independent } \\
\text { work demonstrate CAD skills far below those expected for most students after one } \\
\text { semester of instruction. }\end{array}$ \\
\hline
\end{tabular}


Table 2: Acceptable Portfolio Assessment Results by Year and Curricula

\begin{tabular}{|l|c|c|c|c|c|}
\hline Curricula & \multicolumn{2}{|c|}{ Old Curriculum } & \multicolumn{3}{c|}{ New Curriculum } \\
\hline Year & 2005 & 2006 & 2007 & 2008 & 2009 \\
\hline \% Acceptable & 75 & 81 & 61 & 79 & 80 \\
\hline
\end{tabular}

The percentage of acceptable portfolios improved from 2005 to 2006 then took a marked decline in 2007 followed by a return to historical levels in 2008 and 2009. The increase in acceptable portfolios in 2006 is attributed to logistical changes made to the 6 hour course that provided more continuity to the graphics portion of the course as well as instructor experience in delivering the content. The marked decline in acceptable portfolios in 2007 is attributed to the addition of an independent design project whereas the subsequent improvements were due to changes made in how the design project was assigned and managed.

The design project was added in 2007 after it was determined that the portfolio as originally assigned only included student work that was created by following specific instructions from the textbook or from highly prescribed assignments from the text. It was deemed that adding an independent open-ended design project would provide a better indication of the students' mastery of the engineering tool. The design project was chosen such that a novice student with limited mechanical background and design knowledge could be successful, while at the same time, a student with prior CAD experience from high school would not be bored. The project simply requires the student to design an object consisting of four or more different parts, create solid models of the parts, create an assembly of the object, create detailed dimensioned drawings of the parts, and create an assembly drawing of the object including an exploded view and a bill of materials. In addition to the CAD work, the students are required to write a one-page paper describing their project. The objective of creating a project that works for both the novice CAD student and the experienced CAD student has been successful. The novice students will tend to design a simple object such as a table or bookcase whereas the experienced student will design a more complex object such as an internal combustion engine or guitar and will often include advanced features such as motion simulations or the use of photo-rendering.

In 2007, the project was assigned mid-semester and the students were required to submit their project topic the following week. The project was then submitted at the end of the semester as a section of the portfolio. The project was assessed as part of the portfolio; however the project was graded independently from the portfolio. The marked drop in the percentage of acceptable portfolios was attributed to student procrastination resulting in the submission of incomplete portfolios. For the most part, the procrastinating students successfully solid modeled the parts and the assembly, but greatly underestimated the time or effort required to make the detailed and assembly drawings. In addition, the creation of drawings using the CAD program is covered late in the semester and many students had not completely mastered this skill.

In an effort to combat the procrastination and improve the assessment results, several changes were made for the 2008 offering of the graphics course. First and foremost, some project management guidelines were imposed on the design project to include an intermediate milestone and project update. To this end, the students were required to complete all of their solid models and assembly by an intermediate date (approximately 2 weeks prior to the end of the semester) 
and present their design to the class using a PowerPoint presentation. The presentation adds an element of peer pressure that results in the students taking the project more seriously and provides some very positive role models for the novice students to strive for while allowing the experienced students to show off their skills. The presentation also allows the instructor to provide feedback on the solid models and set the expectation on the completeness of the drawings (it seems as if some students do not quite understand all the project requirements at this point). The intermediate milestone and presentation had the desired impact, resulting in a marked improvement in the percentage of acceptable portfolios in 2008 and continuing into 2009.

A second change made in 2008 was an effort to improve the students' mastery of creating detailed CAD drawings. In the earlier offerings of the course, detailed CAD drawings were covered in the latter half of the course after covering hand sketching, solid modeling of parts, and dimensioning. Although the course objective on creating drawings was rated high on the student survey that measures the self-reported achievement of course objectives, instructor reported input indicated otherwise. This is typical of the experience with indirect assessment where the students' self-report successful achievement of a learning objective measures higher than other direct assessment measures. ${ }^{11}$ In this case, the project was intended to strengthen the students' proficiency in the creation of detailed CAD drawings and concurrent with the changes in the project described above, the topic of detailed CAD drawings was introduced earlier in the semester concurrent with creating multiview hand drawings. The topic was then covered in more depth once dimensioning was covered. This change seemed to work well with the selfreported achievement of the objective, as given by 4 or 5 ratings (agree or strongly agree that the objective was achieved) on a 5-point scale, making a modest improvement from $91 \%$ in 2007 to $94 \%$ in 2008.

However, in 2009, one minor change was made to the delivery of the material that resulted in a $10 \%$ drop in the self-reported achievement of the objective. The change was to introduce creating detailed CAD drawings without including an exercise to create a custom title block. The custom title block was moved later into the semester when students had a more experience with the CAD program, and the students were required to then integrate the title block with the detailed drawing created earlier in the semester, completing essentially the same assignment. In hindsight this did not work well, as there are many elements of the title block such as general tolerance specifications that are integral to the creation of the dimensioned drawing, and by completing these two assignments independently and then combining the results, the integral link between the title block and the dimensioned drawing became lost to some students. The instructors of the Engineering Graphics course still are not completely satisfied with the delivery of the related topics of detailed CAD drawings and dimensioning and tolerancing and plan additional changes in 2010. The success of these changes will be measured using both direct and indirect assessment tools driving the course towards continuous improvement.

\section{Introduction to Engineering}

In the old curriculum, the six hour Introduction to Engineering course covered professional practices, introduction to electrical systems, introduction to mechanical systems, and engineering graphics, and had a robot project. The course contained thirteen objectives beyond the engineering graphics objectives. The course was somewhat a potpourri of disjointed topics 
ranging from ethics, teamwork, design, project management, effective presentations, effective writing, Excel, problem solving, teamwork, analysis of electrical system component and analysis of mechanical system components that was taught by as many as four instructors. In short, this course was what Clausing ${ }^{12}$ states a freshman course should not be; "a hodgepodge of peripheral topics.”

With the introduction of the new curriculum in the Fall of 2007, the engineering graphics content became a separate two-hour course and the remaining content with the exception of Excel was collapsed into the three-hour Introduction to Engineering course. With the creation of the new course, an effort was made to greatly reduce the "hodgepodge of peripheral topics." This was accomplished for the most part by integrating the topics with the robot project. As an example, the old course taught project management from a large corporations' view-point, covering the various management structures seen across industry. Not only is this dry to the average freshman, the covered material had no relationship to the robot project that the students' were engaged in. However; as reported in a survey by Summers and Edmonson, ${ }^{13}$ the integration of project management concepts with student projects can be very effective:

Instructors reporting greater success with student project skill implementation were the ones who also reported that they place requirements on their students to apply their skills to the projects given in the class, whether short or long. These individuals were in the minority. Most of the respondents reported a laissez-faire approach to project management. Many of these same people reported that they were disappointed that students didn't use the skills they had learned. Integrating the use of specific project management skills into the project requirements reinforces and refines the students' ability to use their acquired skills. During this process, students become increasingly aware of their own capabilities and limitations.

Based upon the survey observations of Summers and Edmonson, the project management coverage was reduced and focused on the Gantt chart with the requirement to create and utilize a Gantt chart in managing the robot project. Other similar changes were made and topics such as the electrical and mechanical systems were based solely upon the components as devices utilized in the robot project and teamwork focuses on their robot project team.

A second approach taken to reduce the "hodgepodge of peripheral topics" was to approach some topics from a standpoint of giving the students an appreciation of what engineering is and what engineers do without overwhelming them with detailed concepts and new ideas. This is similar to how Petroski ${ }^{14}$ describes an engineering course analogous to Art Appreciation as:

Engineering students can benefit from an analogous course, in which they are introduced to the nature of engineering, including its methods and challenges, and are taught how to look critically and appreciatively at works of engineering. Mathematics and science prerequisites for first-year engineering students advance their knowledge and skills in those fields but do little to satisfy their drive to understand how tangible things are designed and made - and how they work.

This appreciation approach is utilized as engineering design is introduced through the NOVA program Battle of the X-Planes, which covers the Joint Strike Fighter development. In addition, 
a team presentation on a well known engineering failure provides students an appreciation of engineering, or lack there-of.

There are three ABET outcomes directly assessed in the Introduction to Engineering course. Outcome $\mathrm{f}$ (professional ethics) is assessed utilizing the ASME on-line ethic quiz, outcome $\mathrm{g}$ (effective communications) is assessed utilizing the end of semester robot project presentation, and outcome h (impact of engineering solutions in a global, economic, environmental, and societal context) is assessed utilizing the engineering failures presentation.

Ethics was assessed on the six-hour course through the engineering disasters presentation. However with the number of instructors involved in the course, there was little coordination between the presentation and the delivery of the ethics lecture content. The evaluation of the assessment results indicated the students confused fault or blame with ethical responsibility. In the two years of running of the new Introduction to Engineering course, ethics has been covered utilizing discussion of case studies and of the NSPE and ASME canons. Direct assessment is obtained by utilizing a slightly condensed version of the ASME on-line ethics quiz available at http://professionalpractice.asme.org/Transition/Ethics/Introduction.cfm. The quiz is slightly condensed (from 16 to 12 questions) in order to eliminate several questions deemed to be too indepth or complicated for the freshman level. The scores of the quiz were converted to a 1 to 4 rating and the percentage of acceptable (3 or 4) rating was reported. A quiz raw score of 11 or 12 was deemed an assessment rating of 4 and a quiz raw score of 9 or 10 was deemed an assessment rating of 3 . In 2008, $73 \%$ of the students were assessed with an acceptable rating on ethics; however, in 2009 the acceptable rating dropped to 46\%. The drop was primarily due to the number of students that fell just below the acceptable line with a raw score of 8 on the quiz. End of semester instructor feedback also indicates that this is a difficult topic to cover in two lectures and very dry in the current delivery method. Plans for next years' offering are currently under revision with the objective of improving the delivery of the content as well consideration of changing the assessment method.

Outcome h was not assessed in the six-hour course, but with the change in the assessment of ethics, it was determined that the "impact of engineering solutions in a global, economic, environmental, and societal context" fit well into the engineering disasters presentation assignment. The purpose of the assignment is to provide the students an opportunity to develop their presentation and team skills while exposing the entire class to some historically significant engineering disasters. The students complete the assignment as a team, utilizing the same team as the robot project. The assignment is as follows:

Research an assigned engineering failure to determine the following:

1. Describe the component or system. What was the design intent?

2. Describe the events leading up to the failure.

3. Describe the failure.

4. Describe the loss of property and life caused by the failure.

5. Describe the immediate ramifications of the failure.

6. Describe the post failure analysis that was carried out to determine the cause of the failure.

7. Describe how engineering was changed due to the failure. How are things done differently so that the failure does not repeat? 


\section{Describe the impact of the failure and/or subsequent engineering solution in a global, economic, environmental, and societal context.}

Each team chooses a topic from the following list on a first-come, first-served basis: USS Thresher, Space Shuttle Challenger, Space Shuttle Columbia, Apollo 1, St. Francis Dam, Chernobyl, World Trade Center, Tacoma Narrows Bridge, Union Carbide Bhopal, India, De Havilland Comet, Kansas City Hyatt Regency, Northeastern US/Ontario Electrical Blackout of 2003, or the Minneapolis Bridge Collapse of 2007. The presentations are assessed by three instructors on a 1 to 4 scale using the rubric shown in Table 3.

Table 3: Case Study Assessment Rubric for Outcome h

\begin{tabular}{|c|l|}
\hline Rating & Description \\
\hline 4 & $\begin{array}{l}\text { Students recognize and understand the impact due to the failure and /or subsequent } \\
\text { engineering solution of their assigned case study, and articulate that understanding clearly, } \\
\text { focusing on the applicable global, economic, environmental, and societal context. }\end{array}$ \\
\hline 3 & $\begin{array}{l}\text { Students are aware of the impact due to the failure and /or subsequent engineering solution of } \\
\text { their assigned case study, and can make observations about these considerations at a level to } \\
\text { be expected of engineering students. }\end{array}$ \\
\hline 2 & $\begin{array}{l}\text { Students mention the impact due to the failure and /or subsequent engineering solution, but do } \\
\text { not demonstrate that they are aware of how these considerations relate to their assigned case } \\
\text { study. }\end{array}$ \\
\hline 1 & $\begin{array}{l}\text { Students do not address the impact due to the failure and /or subsequent engineering solution } \\
\text { of their assigned case study }\end{array}$ \\
\hline
\end{tabular}

In 2008 , only $60 \%$ of the students were rated acceptable (rated a 3 or 4 ) in the achievement of outcome $\mathrm{h}$. In a post-semester review of the course, the instructors determined that the students were never taught or shown how to "describe the impact of the failure and/or subsequent engineering solution in a global, economic, environmental, and societal context" and therefore many groups only superficially addressed the outcome. A remedy was developed for the 2009 running of the course. In 2009, the course coordinator created a presentation on the Lake Peigneur disaster and personally gave the presentation to every section of the class a week prior to the students' presentation. Not only did the presentation provide the students an example of the expected depth and breadth of presenting outcome $h$, it showed them how to present all required aspects of the presentation, how to make visually pleasing slides, how to expound upon the slides, and how to properly cite the information that was being presented. Consistent with that reported by Clausing ${ }^{12}$, a marked improvement in the students' presentations was observed when the students were shown how to make the presentation. It should be noted that the course does have a lecture on the dos and don'ts making presentations, however, the students seem to struggle assimilating that information into their own presentations without a concrete example. The assessment of outcome $\mathrm{h}$ improved to $78 \%$ acceptable ratings.

Outcome $\mathrm{g}$ has been assessed using an end of semester presentation on the robot project since the inception of the project in 2005. Starting with the new Introduction to Engineering course in 2007, the robot project itself changed from a remote controlled robot to an autonomous robot requiring computer programming skills. The semester long project has several intermediate tasks that develop the students programming skills, help them become familiar with the motion control and pneumatics components, and understand how to use simple sensors in a feedback 
control loop. The project culminates in the second half of the semester with an open-ended design project requiring the students to build a robot that can sense and subsequently extinguish a candle. During the second to last lab, the students present their approach and design and during the last lab, the students compete to complete the task in the least amount of time.

The presentation assignment is:

Your team will make a presentation explaining your design. The presentation should provide an overview of the challenge, illustrate your schedule through a Gantt chart, cover the design alternatives that you considered, cover your design solution, include a solid model of your robot, detail your rapid prototyped part, and cover your programming including a good flow chart. You are required to turn in a printed copy of your presentation prior to presenting.

Outcome $\mathrm{g}$ is assessed on a 1 to 4 scale using the rubric shown in Table 3. The presentations are assessed in four categories; content, slide quality, presentation skills, and overall effectiveness. The Three instructors assess each presentation and the average ratings across all four categories are reported for assessment.

Table 4: Presentation Assessment Rubric for Outcome g

\begin{tabular}{|c|l|}
\hline Rating & Description \\
\hline 4 & $\begin{array}{l}\text { Students clearly communicate all aspects of their robot project at a level expected of } \\
\text { engineering graduates. }\end{array}$ \\
\hline 3 & $\begin{array}{l}\text { Students clearly communicate most aspects of their robot project at a level expected of } \\
\text { engineering graduates. }\end{array}$ \\
\hline 2 & $\begin{array}{l}\text { Students clearly communicate some aspects of their robot project at a level expected of } \\
\text { engineering graduates. }\end{array}$ \\
\hline 1 & $\begin{array}{l}\text { Students unable to clearly communicate any aspects of their robot project at a level expected } \\
\text { of engineering graduates. }\end{array}$ \\
\hline
\end{tabular}

The percentage of acceptable presentations as rated by an average rating of 3.0 or higher dating back to the old curriculum is shown in Table 5.

Table 5: Acceptable Effective Communications Assessment Results by Year and Curricula

\begin{tabular}{|c|c|c|c|c|}
\hline Curricula & \multicolumn{2}{|c|}{ Old Curriculum } & \multicolumn{2}{c|}{ New Curriculum } \\
\hline Year & 2005 & 2006 & $2008^{*}$ & 2009 \\
\hline \% Acceptable & 94 & 80 & 69 & 68 \\
\hline
\end{tabular}

*the course did not run in 2007 due to changing from a fall to a spring semester course

The first year of the presentation is somewhat of an outlier as the class size was relatively small, the teams relatively large ( 6 to 8 students), the students were individually evaluated, and the evaluators were outside guests from local industry which resulted in extra emphasis on the presentation. As the program grew, individual assessment using outside evaluators was not sustainable; however, team size was reduced to 3 students. In 2005, practice presentations to the instructor were mandatory, in 2006 and 2008, practice presentations were optional and not widely taken advantage of, thus resulting in the elimination of the practice presentations in 2009. As shown in Table 5, the assessment ratings fall below our program's target of $70 \%$ acceptable 
ratings for the new curriculum. In both years, the ratings are primarily driven by the Slide Quality category, where the students tend to use too many words and not enough pictures, drawings, or diagrams. The instructors of the course incorrectly assumed that there would be an improvement in the presentation quality in 2009 based upon the example case study presentation made earlier in the semester. Although the example presentation helped improve the case study presentation where the students could follow a fairly prescribed format, they were unable to carry this into the more open-ended format of the robot project presentation, even though they were the experts on their project. The corrective action planned for 2010 is to bring back the mandatory practice presentation.

\section{Computer Applications in Engineering}

As noted earlier, the original program curriculum did not include programming until the sophomore year, in the lab portion of a dynamics course. The Computer Applications course was created to be offered concurrently with the Introduction to Engineering course. For a programming language, MATLAB was selected. The main reasons for selecting MATLAB were the simplicity of its programming structures and its use in circuits and controls classes later in the curriculum. While MATLAB has many unique functions and commands, its while and for loops and if, if-else, and if-elseif-else logic structures are straightforward and easy to relate to flow charts. Instruction in Excel is also a part of this class. While most students come in with a cursory knowledge of Excel, many have never entered complex formulas or created graphs. Since Excel will probably be the tool they use the most to make most of their calculations in future courses (with the possible exception of their calculators), more in-depth knowledge of Excel will be of great value to the students. The general format of the course is to begin with basic instruction in Excel and MATLAB and then investigate applications with both tools. One of the course objectives is that students will be able to select the appropriate tool for a given problem.

Although there are many MATLAB texts available, the faculty members responsible for teaching the class were not satisfied with those that were reviewed. Many emphasize the efficient use of MATLAB-specific commands, while the approach chosen for creating this class was to use the more generic commands as much as possible so that teaching of the concepts of programming loops and logic is done in the least software-specific manner possible. Also, a goal was to use MATLAB and Excel to solve some of the same problems, so a separate Excel text was not desired. Therefore, a new text was created for the course. ${ }^{15}$ During the initial Spring 2008 offering, a manuscript was used, and in Spring 2009 the published text was used. As a result of using the manuscript, the authors were able to try out the material with students and make some modifications to the final text. Among these modifications were two changes to the order of the chapters. In the manuscript, MATLAB was presented before Excel. When teaching the course for the first time, the order was reversed because the bookstore did not order enough copies of the MATLAB Student Edition, and some students were not able to install MATLAB on their computers until a couple of weeks into the semester. This change was found to be beneficial, since students are more familiar with Excel. Also, a chapter on matrix mathematics was included in the first section (Computational Tools) of the book, while a chapter on simultaneous equations appeared in the second section (Engineering Applications), following a chapter on root finding. In order to flow smoothly from matrix math to simultaneous equations, the matrix math 
chapter was moved to Part 2, immediately before the simultaneous equations chapter. The final ordering of the book chapters is as shown in Table 6.

$\mathbb{0}$
$\stackrel{0}{0}$
$\mathbb{D}$
$\vec{U}$
$\stackrel{N}{0}$
$\overrightarrow{0}$
$\dot{\vec{v}}$ 
Table 6: Chapters of MATLAB/Excel Text

\begin{tabular}{|l|l|}
\hline \multicolumn{2}{|l|}{ Part 1 - Computing Tools } \\
\hline 1 & Computing Tools \\
\hline 2 & Excel Fundamentals \\
\hline 3 & MATLAB Fundamentals \\
\hline 4 & MATLAB Programming \\
\hline 5 & Plotting Data \\
\hline Part 2- Engineering Applications \\
\hline 6 & Finding the Roots of Equations \\
\hline 7 & Matrix Mathematics \\
\hline 8 & $\begin{array}{l}\text { Solving Simultaneous } \\
\text { Equations }\end{array}$ \\
\hline 9 & Numerical Integration \\
\hline 10 & Optimization \\
\hline
\end{tabular}

In the course, topics are covered in the same order as the book chapters. Two additional topics are also covered - vector addition and pivot tables. Vector addition was added because it is a useful topic for future courses and because it allows another solution method - a graphical solution using SolidWorks - to be introduced. Vector addition is also an interesting application in that solving for the two unknowns in a 2-D vector addition problem can be either a linear or non-linear problem, depending on which quantities are unknown. Pivot tables were added at the request of a member of the program's Engineering Advisory Board.

The Computing Tools course supports three ABET outcomes: a (math and science), $g$ (communications), and $\mathrm{k}$ (modern engineering tools). Outcomes $\mathrm{g}$ and $\mathrm{k}$ are accessed directly through student work samples, while outcome a is assessed only indirectly through the student survey of course objectives. In Spring 2007, outcome g was assessed relative to one homework assignment. Only 57\% of the student assignments were rated as satisfactory or superior (3 or 4 on a 4-point scale). The instructors of the course agreed that the quality of written work from student to student and from assignment to assignment was inconsistent, and recommended that a standard template for students to follow might help them to better organize their work. Results from outcome $\mathrm{k}$ assessment were also low, with $35 \%$ of work samples rated 3 or 4 . The assignment assessed, which required the numerical integration of acceleration data to determine velocity and position, may have been difficult for the students to understand, and also occurred very late in the semester.

Student evaluations of achievement of the 14 learning objectives of the course were overall good, with only four objectives receiving less than $70 \% 4$ or 5 ratings (agree or strongly agree that the objective was achieved) on a 5-point scale. Those topics are shown in Table 7. 
Table 7: Low-Rated Course Objectives for Computer Applications in Engineering, Spring 2008

\begin{tabular}{|l|c|}
\hline Objective & $\% 4$ or 5 Ratings \\
\hline I am able to perform numerical integration with MATLAB and Excel. & $70 \%$ \\
\hline $\begin{array}{l}\text { I am able to troubleshoot MATLAB files and correct common } \\
\text { programming errors. }\end{array}$ & $63 \%$ \\
\hline I am able to solve constrained optimization problems with Excel Solver. & $62 \%$ \\
\hline I am able to analyze data with pivot tables with Excel. & $55 \%$ \\
\hline
\end{tabular}

Numerical integration and optimization were the last two topics covered, and so were somewhat rushed and presented at a time when student interest often wanes. The pivot table exercise was complicated by the fact that students had a mixture of Excel versions. While the course materials were written for Excel 2007, many students had Excel 2003. It was decided to specifically list the Excel version on the syllabus in future offerings. Although students rated their ability to troubleshoot MATLAB files relatively low, they clearly made progress throughout the semester in this area. Additional skills in this area will be developed when the students use MATLAB in subsequent courses.

Other assessment results were relatively good ratings for the manuscript ( $80 \% 4$ or 5 ratings on a 5-point scale), and a relatively low amount of work outside of class -3.2 hours average. Also, the prerequisites were rated as adequate by $72 \%$ of students. There were actually no prerequisites for the course. As a result, the math level of students in the course ranged from those in Calculus II to those taking College Algebra for the second time. Most of the College Algebra students, who are actually classified as engineering-intended students, performed poorly in the course. Since these students will require a minimum of five years to complete their degree, there is no reason for these students not to wait a year before taking this course. Therefore, it was agreed to add a co-requisite of Pre-Calculus to the course.

For the second offering of the course in Spring 2009, the topics covered were essentially the same. More assignments were given, and the number of hours outside of class reported by the students rose to an average of 4.2 hours. Standard templates for assignments were posted for students to follow. However, the assessment results for outcome g (communications) were largely unchanged, with $60 \%$ of assignments rated as satisfactory or superior. This result was contrary to the instructors' qualitative evaluation that the overall quality of written assignments was noticeably improved from the previous year. As with the assessment of outcome $\mathrm{k}$ the previous year, this assignment occurred late in the semester, and students may have been busy with other assignments and projects and therefore put less effort into the assignment. In Spring 2010, the assignment for assessment of outcome $\mathrm{g}$ will be selected so that it occurs earlier in the semester.

Assessment of outcome $\mathrm{k}$ (modern tools) was reevaluated. Ideally, outcome $\mathrm{k}$ would be assessed through a project in which the student selected the computing tool to be used and justified their selection. However, since there are a large number of topics to be covered in the course, a project is not practical. Also, since this is an introductory course, the students' abilities to write 
and interpret spreadsheets and program code is a better benchmark for assessment. In the future, outcome $\mathrm{k}$ will be assessed with FE-style questions on the final exam.

Student surveys showed improvement in self-reported achievement of most of the 14 course objectives, with all rated at greater than $70 \% 4$ or 5 on a 5-point scale. The text received ratings of 4 or 5 from $91 \%$ of the students. The prerequisites were rated as adequate by $79 \%$ of the students. However, the department's advisor talked to several students who were taking PreCalculus concurrently with the Computer Applications course who felt that they were unprepared for the math in Computer Applications. Even though calculus is used in the Computer Applications class, it is presented in a way that exposure to calculus is not required. For example, numerical integration is presented by defining a definite integral as the area under a curve between two values, and the integral is evaluated by finding that area. This approach was designed to complement the students' math courses and give students a better understanding of calculus topics. However, this approach may be intimidating for students not ready for calculus. As with the rationale for excluding College Algebra students, because students taking PreCalculus in the spring semester will require at least five years to graduate, requiring them to wait a semester or year before taking Computer Applications will not delay their graduation. Therefore, the co-requisite for the course will be changed to Calculus I.

\section{Discussion}

The three first-year courses, Engineering Graphics, Introduction to Engineering, and Computer Applications in Engineering, have effectively utilized both direct and indirect assessment to make improvements to the individual courses and the overall engineering program. The measure of the improvements can be made from the assessment results themselves, or through other indicators such as retention, instructor feedback, and informal student feedback.

The utilization of a continuous improvement approach has resulted in changes to the instructional approach, the assessment assignment, or the course level objectives in all three firstyear courses. The assessment results of outcome $\mathrm{k}$ have improved in the Engineering Graphics course primarily by making minor modifications to the portfolio assignment that have effectively reduced student procrastination.

The assessment results of outcome h have also improved in the Introduction to Engineering course by simply providing the students with a concrete example from upon which they could learn the expectations. On the other hand, the assessment results of outcome $\mathrm{g}$ did not benefit from the concrete example that was temporally displaced from the assessment assignment, indicating that another approach must be taken to improve achievement of outcome g. The poor achievement of outcome $\mathrm{f}$ in the same course has resulted in a re-visiting of both the instructional approach and questioning the appropriateness of the objective within the course.

Similar results are being obtained in the Computer Applications in Engineering course in the assessment of outcome $\mathrm{g}$ and outcome $\mathrm{k}$. Implementing a standard format for the documentation of programming exercises resulted in little improvement in the assessment of outcome $\mathrm{g}$, and contrary to instructors' feedback that there was an overall improvement in assignment format for the course. While the intent is not to cherry pick assignments that will ensure good assessment, certainly understanding why a particular assessment tool shows unsatisfactory achievement of 
the objective or outcome is paramount to continuous improvement. In this case, choosing one of the last assignments of the semester while not placing any additional emphasis on the assignment likely doomed the results. The proposed corrective action is to change the assessed assignment to one that occurs earlier in the semester. The analysis of the cause of the poor assessment of the achievement of outcome $\mathrm{k}$ has likewise caused us to re-evaluate the assessment tool from an assignment to FE-style exam questions that test the students' understanding of programming concepts such as loops and logic.

The utilization of retention statistics in the evaluation of the improvement of ECU's first-year program is problematic. The engineering program is growing at an annual rate of greater than $25 \%$ and there are many factors that influence retention in the program, such as the implementation of a learning community, improvements in tutoring services, greater recruiting and outreach programs, and the close cooperation of the engineering and mathematics departments . ${ }^{16}$ These programs are all driven at improving retention and thus make it very difficult to use retention as a metric of successful improvement of the first-year courses.

On the other hand, both instructor and student feedback has been very positive. Presently, according to instructor feedback, the Engineering Graphics course is very close to being a mature course, one requiring only minor changes from semester to semester. Informal student feedback indicates that great strides in the Introduction to Engineering course. Many students make comments at the end of the semester telling us of the great learning experience they had from the robot project. The students tell how they wish they would have understood the importance of teamwork and project management earlier on in the semester, indicating that there are still opportunities for improvements to the course. The Computer Applications in Engineering course is the newest of the three courses and instructor feedback indicates improvements from the first to second year in the quality and effectiveness of the course delivery and informal student feedback primarily via the academic advisor has resulted in changing the math co-requisite of the course to Calculus.

\section{Conclusion}

The implementation and use of ABET assessment in a continuous improvement approach has been effective in making improvements to a first-year program. The evaluation of the cause of unsatisfactory achievement of ABET outcomes and the implementation of corrective action to include changes to the instructional approach, the assessment assignment, or the course level objectives in all three first-year courses has resulted in improvements to the courses and a corresponding improvement in the achievement of some of the outcomes. Changes continue to be implemented to further improve the first-year program.

\section{References}

1. Coward, H., Ailes, C., and Bardon, R., "Progress of the Engineering Education Coalitions," Final Report prepared for the Engineering Education and Centers Division, National Science Foundation by SRI International, May 2000. Accessed from www.sri.com/policy/csted/reports/sandt/documents/Coalition.pdf. 
2. Kauffmann, P., Rogers, R., and Lunsford, P., “A Case Study: Development of a Practice Oriented Engineering Program with Implications for Regional Economic Development," Proceedings of the 2004 American Society for Engineering Education Annual Conference \& Exposition.

3. Brannan, K.P. and Wankat, P.C., "Survey of First-Year Programs", Proceedings of the 2005 American Society for Engineering Education Annual Conference \& Exposition.

4. Crockett, R., Koch, M., and Walsh, D., “A Freshman Design Experience Using RPT,” Proceedings of the 2004 American Society for Engineering Education Annual Conference \& Exposition.

5. Besterfield-Sacre, M., Atman, C., and Shuman, L., "Characteristics of Freshman Engineering Students: Models for Determining Student Attrition in Engineering," Journal of Engineering Education, v. 86, no. 2, April 1997.

6. Dee, K. and Livesay, G., "First-Year Students Who Leave Engineering: Learning Styles and Self-Reported Perceptions," Proceedings of the 2004 American Society for Engineering Education Annual Conference \& Exposition.

7. Peters, M., Chisholm, P., and Laeng, B., "Spatial Ability, Student Gender, and Academic Performance," Journal of Engineering Education, v. 84, no. 1, January 1995.

8. Sorby, S. and Baartmans, B., "The Development and Assessment of a Course for Enhancing the 3-D Spatial Visualization Skills of First Year Engineering Students," Journal of Engineering Education, v. 89, no. 3, July 2000 .

9. Howard, W. and Musto, J., "The Assessment Workshop: A Tool for Promoting Faculty Involvement," Proceedings of the 2006 American Society for Engineering Education Annual Conference \& Exposition.

10. Felder, R. and Brent, R., "Designing and Teaching Courses to Satisfy the ABET Engineering Criteria," Journal of Engineering Education, v. 92, no. 1, January 2003.

11. Sarin, S. and Headley, D., "Validity of Student Self-Assessments," Proceedings of the 2002 American Society for Engineering Education Annual Conference \& Exposition.

12. Clausing, A. “A Successful Freshman Engineering Course: an Active Learning Experience," Proceedings of the 1998 American Society for Engineering Education Annual Conference \& Exposition.

13. Summers, D. and Edmonson, C., "Are We Asking Our Students to Do Too Many Projects? It Depends," Proceedings of the 2004 American Society for Engineering Education Annual Conference \& Exposition.

14. Petroski, H., "Engineering Appreciation," Prism, American Society for Engineering Education, December, 2009.

15. Musto, J., Howard, W., and Williams, R., Engineering Computations: An Introduction using MATLAB® and Excel®, McGraw Hill, NY, 2009.

16. Brown, E. and Ries, H., "The Engineering/Math Committee: A Successful Collaboration at East Carolina University," Proceedings of the 2009 American Society for Engineering Education Annual Conference \& Exposition. 